\title{
Endoscopic pancreatic stenting in pancreatic cancer
}

\author{
Guido Costamagna MD FACG ${ }^{1}$, Petros Alevras MD ${ }^{1}$, Francesco Palladino MD ${ }^{1}$, Fernando Rainoldi MD ${ }^{1}$, \\ Massimiliano Mutignani $\mathrm{MD}^{1}$, Alessio Morganti $\mathrm{MD}^{2}$
}

G Costamagna, P Alevras, F Palladino, F Rainoldi, M Mutignani, A Morganti. Endoscopic pancreatic stenting in pancreatic cancer. Can J Gastroenterol 1999;13(6):481-487. Most pancreatic carcinomas are unresectable at the time of diagnosis; therefore, palliative treatment is very often the main concern of clinicians in this setting. The main symptoms resulting in the need for palliation in pancreatic cancer are obstructive jaundice, duodenal obstruction and pain. Therapeutic endoscopy plays a major role in the palliation of obstructive jaundice by stent placement into the biliary ducts. Initial experience has also been gained recently with endoscopic placement of expandable metallic stents to treat gastric outlet obstruction. Much less is known about the possible role of endoscopic pancreatic stenting in patients with unresectable pancreatic carcinoma. The main indication for pancreatic ductal stenting is 'obstructive' pain related to meals in patients with dilated main pancreatic duct beyond the stricture and intraluminal brachyradiotherapy. The technique of endoscopic pancreatic stenting does not substantially differ from that applied on the biliary tree. When technically possible, placement of 10 French plastic stents is preferred. According to the authors' indications, only about $15 \%$ of patients with advanced pancreatic cancer ( 55 of 355 in the present study) may potentially benefit from this technique. Pancreatic stenting may be obtained in more than $80 \%$ of these selected patients, with low morbidity (less than $10 \%)$ and no procedure-related mortality. According to the authors of the present and other studies reported in the literature, about $60 \%$ of patients treated because of 'obstructive' pain become symptom-free, and another $20 \%$ to $25 \%$ significantly reduce the amount of analgesic drugs required. Intraluminal brachyradiotherapy with ${ }^{192}$ iridium in the main pancreatic duct is a feasible and safe method to deliver high radiation doses to the tumour while sparing adjacent organs. Brachyradiotherapy may be performed alone or in conjunction with external beam radiotherapy. Because of the small number of patients suitable for this treatment, only a multicentre study will be able to detect whether intraluminal brachyradiotherapy in pancreatic cancer may have any positive impact on survival.

Key Words: Endoscopy; Pancreatic cancer; Pancreatic stenting

\section{Endoprothèse pancréatique endoscopique dans le cancer du pancréas}

RÉSUMÉ : La plupart des cancers du pancréas sont impossibles à réséquer au moment du diagnostic. Par conséquent, le traitement palliatif est souvent le premier objectif des médecins dans ce contexte. Les principaux symptômes justifiant le traitement palliatif dans le cancer du pancréas sont l'ictère obstructif, l'obstruction duodénale et la douleur. L'endoscopie thérapeutique joue un rôle de tout premier plan dans le traitement palliatif de l'ictère obstructif par l'installation d'endoprothèses dans les voies biliaires. On a aussi expérimenté récemment l'installation endoscopique d'endoprothèses métalliques extensibles pour traiter une obstruction du défilé gastrique. On en connaît beaucoup moins sur le rôle possible de l'endoprothèse pancréatique endoscopique chez les patients atteints d'un cancer du pancréas non réséquable. La principale indication de l'endoprothèse du canal pancréatique est la «douleur obstructive» liée à la prise des repas chez les patients présentant une dilatation du canal pancréatique principal au-delà de la stricture et une brachyradiothérapie intraluminale. La technique de l'endoprothèse pancréatique endoscopique

voir page suivante 
ne diffère pas substantiellement de celle de l'arbre biliaire. Lorsque l'intervention est techniquement possible, on préfere recourir à des endoprothèses de plastique French de calibre 10. Selon les indications des auteurs, environ $15 \%$ seulement des patients atteints d'un cancer du pancréas avancé ( 55 sur 355, dans la présente étude) peuvent bénéficier de cette technique. L'endoprothèse pancréatique peut être effectuée chez plus de $80 \%$ de ces patients sélectionnés avec un faible taux de morbidité (moins de $10 \%$ ) et aucune mortalité associée. Selon les auteurs de la présente étude et d'autres études publiées, environ $60 \%$ des patients traités pour douleur obstructive deviennent asymptomatiques et 20 à $25 \%$ des autres consomment significativement moins d'analgésiques. L'administration d'une brachyradiothérapie intraluminale à $\mathrm{l}^{192}$ iridium au niveau du canal pancréatique principal est une méthode faisable et sûre pour administrer de fortes doses de radiation sur la tumeur tout en épargnant les organes adjacents. La brachyradiothérapie peut être effectuée seule ou en association avec une radiothérapie externe. En raison du faible nombre de patients qui sont de bons candidats pour ce type de traitement, seule une étude multicentrique pourrait permettre de déceler si la brachyradiothérapie intraluminale peut exercer un impact positif sur la survie dans le cancer du pancréas.
$\mathrm{P}$ ancreatic carcinoma is the fourth leading cause of cancer death in men in the United States, after lung, colon and prostate cancer. More than 24,000 people die of this disease each year in this country $(1,2)$. Because of early spread of the disease, fewer than $20 \%$ of affected patients are candidates for surgical resection at diagnosis; fewer than $20 \%$ of patients survive one year after diagnosis, with an overall five-year survival rate of less than $3 \%(1,2)$.

Despite this dramatic and disheartening picture, major complications engendered by pancreatic cancer, mainly jaundice resulting from neoplastic compression or invasion of the common bile duct (CBD), intestinal obstruction and pain, very often require treatment aimed at improving the quality of residual life in these patients. Therefore, physicians are almost always called to face the issues of palliation in this setting.

Palliation of pancreatic cancer has traditionally been mostly surgical, until the advent in the late 1970s of nonoperative endoscopic and radiological techniques, which very quickly were shown to be able to provide less aggressive and equally effective biliary drainage in jaundiced patients compared with surgery $(3,4)$. Today, endoscopic biliary drainage by stent insertion is accepted as the first-line treatment modality in the clinical setting of malignant obstructive jaundice in most instances.

Gastric outlet obstruction from duodenal compression or invasion by pancreatic cancer has also been traditionally dealt with by surgeons (5). Only recently, nonsurgical alternatives have come out thanks to the technological improvement of self-expandable metal mesh stents, which may now be applied perorally into the strictured duodenal lumen (6-8). Clinical experience with duodenal self-expanding stents in the setting of pancreatic cancer is still scant, but promising results have been reported by several groups in the literature $(7,8)$.

Pain occurs in a very high proportion of patients with advanced pancreatic cancer; it is often the most distressing and incapacitating symptom affecting these patients (9). Pain is probably the result of multiple factors, including neoplastic infiltration of nerve ends of pancreatic and peripancreatic tissue, and obstruction of the main pancreatic duct (MPD) causing upstream dilation and ductal hypertension (10). Pseudocysts resulting from attacks of acute obstructive pancreatitis secondary to neoplastic strictures of the MPD may also cause pain in a small number of patients. Until now, only little attention has been paid to the potential role of en- doscopic pancreatic drainage in the treatment of obstructive pain in this setting.

Finally, it has been suggested that external beam radiotherapy (with or without concomitant chemotherapy) may provide palliation and perhaps a small advantage in survival for patients with advanced pancreatic carcinoma; intraluminal radiotherapy with positioning of ${ }^{192}$ iridium wires directly in the MPD after endoscopic pancreatic drainage could be the ideal complement of external beam radiotherapy in a subset of patients with locally advanced non-metastatic pancreatic carcinoma (11-14).

The aim of this paper is to review the possible indications, the technique and the results of endoscopic pancreatic stenting in patients with advanced, unresectable pancreatic carcinoma.

\section{INDICATIONS OF ENDOSCOPIC PANCREATIC DRAINAGE IN PANCREATIC CANCER}

Two main indications of pancreatic ductal stenting in patients with pancreatic carcinoma may be envisaged: 'obstructive' pain and intraluminal brachytherapy. Another exceptional indication is pancreatic ductal infection secondary to endoscopic manipulation, ie, pancreatography and/or pancreatic ductal sampling (stricture brushing and biopsy).

Pain occurs in $80 \%$ to $85 \%$ of patients with advanced disease. It is one of the most important factors that define the quality of life and, therefore, has to be considered a main concern of palliative therapy.

Schematically, two main patterns of pain are encountered. Chronic, continuous, dull pain, unrelated to meals and located in the upper abdominal quadrants, often radiating to the back is present in the vast majority of patients. This is presumably due to neoplastic infiltration of sympathetic nerve ends and of pancreatic and peripancreatic tissue. Tumour spread is often shown to involve the retroperitoneum in the area of splanchnic vessels. Besides pharmacological treatment with nonsteroidal antiinflammatory drugs (NSAIDs) and opioids, invasive management is based mainly on celiac plexus block with alcohol (15-17). In turn, in a minority of patients (about 15\%) pain occurs mainly in relation to meals; it is located at the epigastrium and left hypochondrium, and radiates to the left back, starting a few minutes after the end of the meal and lasting for 1 to $2 \mathrm{~h}$. This kind of pain may be as violent and incapacitating as the 'chronic' pain and may cause the patient to fast, 

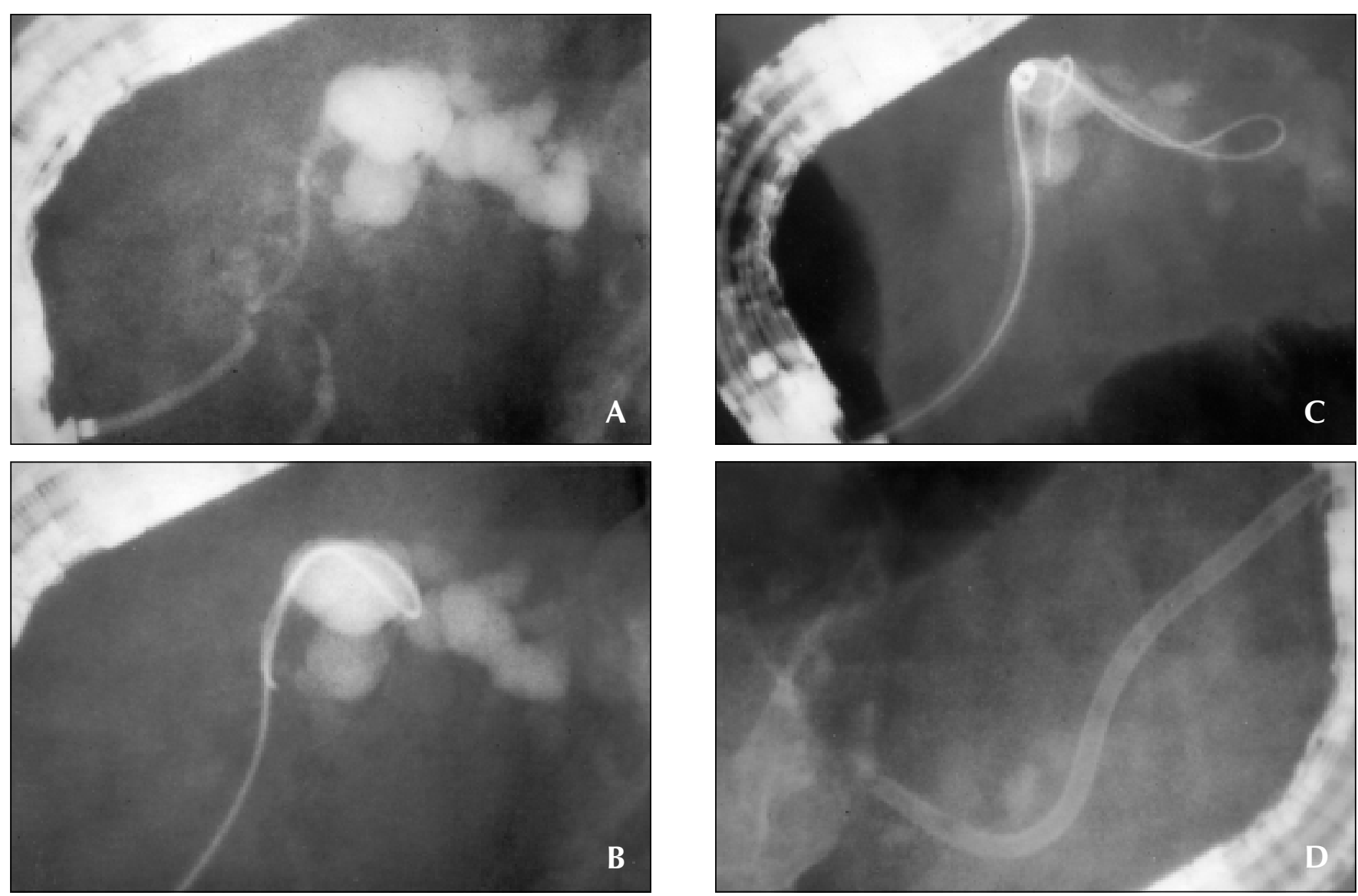

Figure 1) A Pancreatic duct that has been cannulated through the minor papilla. Pancreatography shows a long malignant stricture that involves the main pancreatic duct and its confluence with Santorini duct, and upstream obstructive chronic pancreatitis. B A hydrophilic guidewire has been negotiated through the stricture. C Coaxial dilation of the stricture with an 8.5 French Soehendra dilation catheter before stent insertion. D An 8.5 French plastic stent has been inserted and the duct is already empty of contrast medium

eventually leading to starvation. This postprandial pain pattern closely resembles that of chronic pancreatitis; it is quite always associated with characteristic ductal abnormalities at pancreatography, ie, obstruction of the MPD with upstream dilation of the ductal system, and may, therefore, be defined as 'obstructive' $(10,18)$.

In patients with advanced pancreatic cancer, selected on the basis of concomitant 'obstructive' pain and MPD dilation, the aim of endoscopic insertion of a stent across the pancreatic stricture is the decompression of the ductal system to avoid ductal hypertension (19-24).

While results of chemotherapy for unresectable pancreatic carcinoma are still disappointing (25), some studies published in the 1970s dismissed the presumed radioresistance of these neoplasms by making apparent the ability of external beam radiotherapy (ERT) to prolong survival and control symptoms in advanced cases $(26,27)$. Survival of patients treated with ERT improves in relation to the dose delivered $(26,27)$; however, the presence of critical radiosensitive organs such as the liver, kidney, small intestine and bone marrow limits the dose that can be delivered to this site. Thus, much interest has been directed toward the application of methods that enable the concentration of radiation treatment such as conformal radiotherapy (28) or precision high dose radiotherapy $(29,30)$, intraoperative radiotherapy $(31,32)$ and interstitial radiotherapy $(33-35)$. Within this trend some reports of intraluminal brachytherapy (ILBT) in patients with neoplastic jaundice from pancreatic carcinoma have been published (36); these studies were characterized by the positioning of linear radioactive sources into the extrahepatic bile ducts. ILBT, which allows the delivery of high radiation doses to limited volumes over a short time, was shown to be effective palliation in esophageal, bronchial and rectal carcinoma. The same technique may be applied to pancreatic carcinoma by placing a ${ }^{192}$ iridium wire source directly into the Wirsung duct, provided that the pancreatic stricture has been bypassed with an endoscopic drain or stent.

Finally, patients with pancreatic carcinoma in whom an endoscopic pancreatography or other endoscopic manipulations such as brushing or biopsy of the MPD stricture have been performed may occasionally develop septic complications in the undrained dilated pancreatic ducts; pancreatic ductal drainage with stent placement may thus be required 


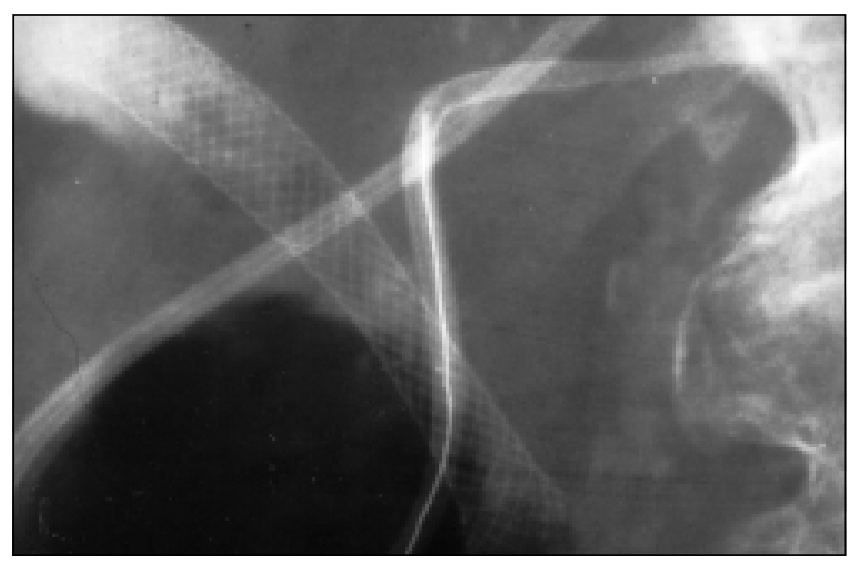

Figure 2) A biliary Wallstent inserted into a 76-year-old man with locally advanced pancreatic cancer. ${ }^{192}$ Iridium wire is carried out through and 8 French nasopancreatic drainage, bypassing the pancreatic duct stricture

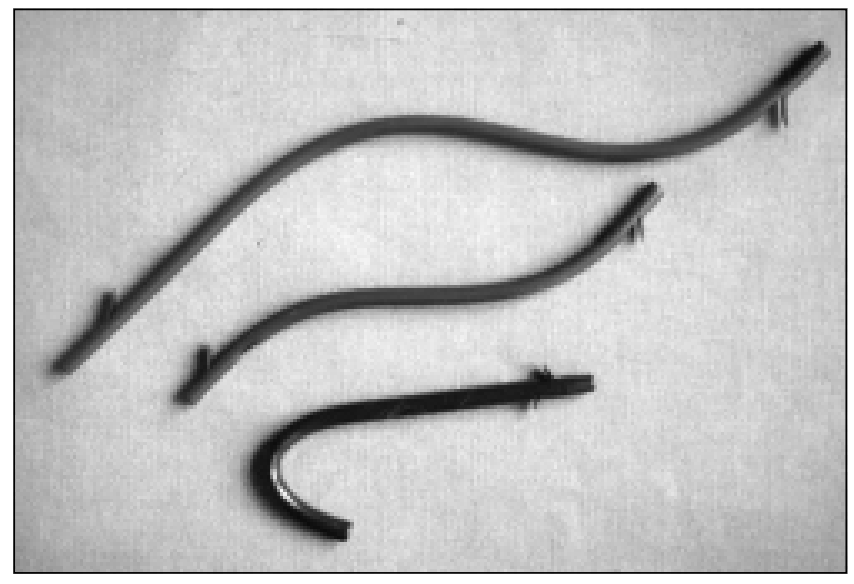

Figure 3) Pancreatic stents of different shapes to fit the pancreatic duct anatomy

to facilitate evacuation of purulent material and to re-establish a good pancreatic-duodenal flow.

\section{TECHNIQUE OF ENDOSCOPIC PANCREATIC DRAINAGE IN PANCREATIC CANCER}

The technique of pancreatic ductal drainage does not substantially differ from that applied to the biliary aspect (Figure 1). If the patient is jaundiced, biliary sphincterotomy before stent insertion into the CBD is mandatory to keep the pancreatic orifice accessible. On the contrary, endoscopic pancreatic sphincterotomy is seldom strictly necessary to ease access to the duct in patients with pancreatic cancer. Access through the minor papilla may be needed in cases of pancreas divisum or of 'dominant' Santorini duct anatomy (ie, patients with normally fused pancreas but with a distorted connection between the ventral and the dorsal duct, making the access to the MPD easier through the duct of Santorini). Deep cannulation of the MPD is then performed with a diagnostic catheter and a hydrophilic guidewire $\left(0.035^{\prime \prime}\right.$ as a rule, but sometimes thinner gauges are required), which is manipulated through the stricture and advanced to the tail of
TABLE 1

Indications of endoscopic pancreatic drainage for pancreatic cancer in $\mathbf{5 5}$ patients

\begin{tabular}{lc}
\hline Indication & Number of patients \\
\hline 'Obstructive' pain & 50 \\
Intraluminal brachytherapy & 8 \\
Pancreatic infection & 1 \\
\hline
\end{tabular}

the pancreas. J-tipped guidewires are often used in this setting because they have the advantage of not projecting into the secondary ducts beyond the stricture. The catheter is then advanced over the guidewire, which may then be replaced with a teflonated stiffer one. Mechanical dilation with catheters of increasing diameter (Soehendra type dilators up to 10 French or coaxial Cunningham-Cotton sleeve of 9.5 French, Wilson-Cook Inc, Winston Salem, North Carolina) is performed systematically before any attempt to place a stent because the stricture hardness is always unpredictable. Supplemental sedation is often required during dilation because the procedure is generally painful. Pneumatic dilation with high pressure balloons is seldom used in the pancreatic duct in our experience. If the stricture cannot be dilated up to a sufficient diameter (at least 7 French) a nasopancreatic drain of 5 to 6 French is left in place overnight to act as a dilation device; stents of larger diameter can always be inserted at a second attempt after 24 to $48 \mathrm{~h}$. If ILBT has been planned, a nasopancreatic drain of at least 8 French has to be placed to allow the insertion of the ${ }^{192}$ iridium wire preloaded catheter (Figure 2). As in the biliary ducts, large-bore 10 French plastic stents are preferred for pancreatic drainage; straight (Amsterdam-like) or anatomically preshaped (Cremer or Costamagna pancreatic stents, Wilson Cook Inc; Olympus Co, Tokyo, Japan) (Figure 3). If large-bore stents are implanted, multiple side flaps to prevent dislocation are not necessary. The use of 5 French stents is not recommended because they tend to occlude in a short time. Stents of 7 French to 8.5 French may be used if mechanical dilation up to 10 French cannot be achieved. The stent length is chosen according to the location of the stricture and may vary between $3 \mathrm{~cm}$ and $12 \mathrm{~cm}$. If the stricture is located in the head of the pancreas, as it occurs in most patients, additional side holes to prevent blockage of secondary ducts, as proposed by some authors, are not necessary. Large-bore pancreatic stents are almost always rapidly effective in decompressing the ducts immediately after their release. It is often possible to record a significant shrinkage of the ducts at the end of the procedure.

\section{PERSONAL EXPERIENCE}

Among 355 patients with pancreatic cancer who underwent ERCP in a nine-year period, 55 patients with unresectable tumour (15.5\%) had one or more indications for endoscopic pancreatic drainage. Indications are listed in Table 1. There were 37 males and 18 females with a mean age of 71.5 years (range 45 to 94 years). 
Technical success was reached in 45 of 55 patients $(81.8 \%)$. Failures in 10 patients were due to unsuccessful opacification of the pancreatic duct, impossible negotiation of the guidewire across the stricture and inability to dilate the stricture itself. Hydrophilic polymer-coated guidewires (Terumo Radiofocus, Terumo Corp, Tokyo, Japan) are the cornerstone of successful drainage. After our initial experience, when the success rate was only $67 \%$ and all the failures had occurred before these guidewires became available, the success rate increased to $86 \%$.

Stents were inserted at the first attempt in $59.4 \%$ and at a second attempt in $40.6 \%$.

Immediate complications were recorded in four patients (8.9\%): Wirsungrrhagia in one, postsphincterotomy bleeding in two and stent dislodgement in one. All the complications were managed endoscopically without mortality. A total of 46 stents were employed ( 7 French $n=18 ; 8.5$ French $n=12 ; 10$ French $n=15 ; 11.5$ French $n=1)$.

Eight patients received ILBT via a nasopancreatic drain with ${ }^{192}$ iridium wire (30 to $50 \mathrm{~Gy}$ ), in three instances combined with ERT (39.6 to 50.4 Gy) and in five without.

Three patients have been lost at follow-up. Among $34 \mathrm{pa}-$ tients treated for 'obstructive' pain who did not undergo ILBT, $21(61.7 \%)$ had total resolution of pain, nine (26.5\%) experienced partial resolution and four (12\%) had no benefit. Seven patients $(20.5 \%)$ are still alive after a mean follow-up of 91 days (range 24 to 245 days), while 27 (79.5\%) died after a mean survival of 216 days (range 19 to 719 days).

Among patients who underwent pancreatic stenting and ILBT, five $(62.5 \%)$ had total resolution of pain and three (37.5\%) partial resolution requiring minor analgesic treatment. All patients have been followed until death. Median survival was 285 days in this group (range 241 to 1110 days). One- and two-year survival rates were $42.8 \%$ and $14.3 \%$, respectively.

\section{DISCUSSION}

The majority of patients with pancreatic carcinoma have unresectable lesions at the time of diagnosis; hence palliative treatment is the main concern of clinicians in this setting. The major role of endoscopy in palliation of obstructive jaundice by stent placement is well established $(37,38)$. Initial experience has recently been gained with metallic selfexpandable stents in the treatment of gastric outlet obstruction (6-8). Less is known about the role of endoscopic pancreatic stenting in patients with unresectable pancreatic carcinoma.

In 1989, Harrison and Hamilton (19) reported a case suggesting the usefulness of pancreatic drainage for pain control in a patient with pancreatic cancer. In 1993, we reported a series of 12 patients with unresectable pancreatic cancer associated with upstream dilation of the MPD and 'obstructive' pain (20). We were able to insert stents in eight of 12 patients; clinical success in pain resolution was observed in seven of eight patients, all of whom were able to discontinue NSAIDs and/or narcotics. The four patients in whom the procedure failed continued to experience pain until their
TABLE 2

Results of endoscopic pancreatic stenting in patients with pancreatic cancer

\begin{tabular}{|c|c|c|c|c|}
\hline $\begin{array}{l}\text { Author, year } \\
\text { (reference) }\end{array}$ & $\begin{array}{c}\text { Number of } \\
\text { patients }\end{array}$ & $\begin{array}{c}\text { Stent } \\
\text { (French) }\end{array}$ & $\begin{array}{c}\text { Number of } \\
\text { patients } \\
\text { successfully } \\
\text { treated } \\
\end{array}$ & $\begin{array}{l}\text { Pain } \\
\text { resolution }\end{array}$ \\
\hline $\begin{array}{l}\text { Harrison and } \\
\text { Hamilton, } 1989 \\
\text { (19) }\end{array}$ & 1 & 7 & 1 & Yes \\
\hline $\begin{array}{c}\text { Costamagna et al, } \\
1993(20)\end{array}$ & 12 & $7-10$ & 8 & $\begin{array}{l}7 \text { total } \\
1 \text { partial }\end{array}$ \\
\hline $\begin{array}{c}\text { Ashby and Simon, } \\
1995(21)\end{array}$ & 5 & $5-11.5$ & 5 & $?$ \\
\hline $\begin{array}{l}\text { Lichtenstein et al, } \\
1995 \text { (22) }\end{array}$ & 5 & $5-7$ & 5 & $\begin{array}{l}3 \text { total } \\
2 \text { no }\end{array}$ \\
\hline $\begin{array}{l}\text { Tham et al, } 1997 \\
\qquad(23)\end{array}$ & 9 & $5-7$ & 9 & $\begin{array}{l}5 \text { total } \\
2 \text { partial } \\
2 \text { no }\end{array}$ \\
\hline $\begin{array}{l}\text { Alcocer et al, } 1998 \\
\quad(24)\end{array}$ & 19 & $7-10$ & 15 & $\begin{array}{c}8 \text { total } \\
4 \text { partial } \\
3 \text { no }\end{array}$ \\
\hline
\end{tabular}

? Data not provided

deaths. In this series, patients were selected on the basis of morphological changes in the pancreatic duct and of obstructive-like pain, similar to that related to chronic pancreatitis. Actually, pancreatic stenting had been applied to patients with chronic calcifying pancreatitis (39-43) to relieve obstruction and to restore pancreaticoduodenal flow since 1985 (39); pain relief results were reported to be excellent with $94 \%$ of early responders. Several other experiences have been reported in the literature showing good short term pain relief results, ranging from $74 \%$ to $86 \%$ (39-43). Long term results of pancreatic stenting in chronic pancreatitis are less enrapturing, mostly because stents tend to become occluded, or at least clinically ineffective, at a mean interval of 10 months in our experience (20).

According to our experiences and others reported in the literature (19-24) pancreatic stenting may also play a role in pain relief in a subset of patients with pancreatic cancer (approximately $15 \%$ of the entire population) selected on a morphological and clinical basis; about $60 \%$ of these patients experience complete disappearance of pain and another $20 \%$ to $25 \%$ are able to reduce significantly the amount of analgesic drugs required (Table 2). Long term patency of pancreatic stents in this setting has much less importance than in the setting of chronic pancreatitis because of the limited life expectancy of patients with advanced pancreatic cancer. Pancreatic stenting may thus be considered to be part of a multidisciplinary therapeutic approach to pain control in pancreatic cancer.

Endoscopic pancreatic drainage may also be applied to ILBTs. ILBT consists of positioning a radioactive source in the lumen of cavitary organs to deliver high doses of radiation locally to the tumour, sparing the adjacent organs. For pancreatic cancer, the radioactive source can be placed in the biliary or in the pancreatic duct according to the spatial development of the neoplasia. Actually, indications of ILBT 
are limited to those biopsy proven, locally advanced, small (less than $3 \mathrm{~cm}$ in diameter) tumours that develop concentrically to the lumen. The latter condition is very important because the source has to be positioned in the central part of the tumour so that biologically significant radiation doses can be delivered to it. Our experience only demonstrates that ILBT in the MPD is technically feasible, carries low complications and toxicity, and may have some impact on survival. If the limited number of patients who meet the criteria for ILBT is considered, a meaningful evaluation of the real impact that this treatment may have on pancreatic cancer requires multicentric studies.

\section{CONCLUSIONS}

The majority of patients with pancreatic carcinoma have unresectable lesions at the time of diagnosis. Palliative treatment is, therefore, very often the main concern of clinicians in this setting. The major role of endoscopy in palliation of obstructive jaundice by stent placement is well established. Initial experience has recently also been gained with metallic expandable stents in the treatment of gastric outlet obstruction. Less is known about the role of endoscopic stent-

\section{REFERENCES}

1. Yeo C, Cameron L. The pancreas. In: Textbook of Surgery. The Biological Basis of Modern Surgical Practice, 40th edn. Philadelphia: WB Saunders Company, 1991:1093-7.

2. Reber HA. Pancreas. In: Schwartz S, Shires T, Spencer F, eds. Principles of Surgery, 6th edn. New York: McGraw Hill, 1994:1401-32.

3. Molnar W, Stockum AE. Relief of obstructive jaundice through percutaneous transhepatic catheter: a new therapeutic method. Am J Radiol 1974;122:346-67.

4. Soehendra N, Reynders-Frederix V. Palliative gallengangs drainage. Dtsch Med Wochenschr 1979;104:206-7.

5. Lucas CE, Ledgerwood AM, Bender JS. Antrectomy with gastrojejunostomy for unresectable pancreatic cancer causing duodenal obstruction. Surgery 1991;110:583-90.

6. Lichtenstein DR, Carr-Locke DL. Endoscopic palliative treatment in pancreatic carcinoma. Surg Clin North Am 1995;75:969-88.

7. Feretis C, Benakis P, Dimopoulos C, et al. Palliation of malignant duodenal obstruction with self-expanding metal stents. Endoscopy 1996;28:225-8.

8. Keymling M, Wagner HJ, Vakil N, Knyrim K. Relief of malignant duodenal obstruction by percutaneous insertion of metal stents. Gastrointest Endosc 1992;339:439-41.

9. Kiser MH, Barkin J, Maclntyre JM. Pancreatic cancer: assessment of prognosis by clinical presentation. Cancer 1985;56:397-402.

10. Lebowitz AH, Lefkowitz M. Pain management of pancreatic carcinoma: a review: Pain 1988;36:1-11.

11. Montemaggi P, Morganti A, Dobelbower R, et al. Role of intraluminal brachytherapy in extrahepatic bile duct, and pancreatic cancers: Is it just for palliation? Radiology 1996;199:861-6.

12. Montemaggi $P$, Costamagna G, Dobelhower R, et al. Intraluminal brachytherapy in the treatment of pancreas and bile duct carcinoma. Int J Radiother Oncol Biol Phys 1995;32:437-43.

13. Montemaggi P, Morganti A, Smaniotto P, Luzi S, Zicarelli L, Cellini N. Carcinoma of the pancreatic head area therapy: intraluminal brachytherapy. Rays 1995;20:338-49.

14. Alden ME, Mohiuddin M. The impact of radiation dose in combined external beam and intraluminal Ir-192 brachytherapy for bile duct cancer. Int J Radiother Oncol Biol Phys 1994;28:945-51.

15. Owitz S, Koppow S. Celiac plexus block: an overview. Mt Sinai J Med 1983;50:486-90.

16. Sharfman WH, Walsh DT. Has the analgesic efficacy of neurolytic celiac plexus block been demonstrated in pancreatic cancer pain? Pain 1990;41:267-71.

17. Copping S, Willix R, Kraft RO. Palliative chemical splachnicectomy. Arch Surg 1969;98:418-20. ing in patients with unresectable pancreatic carcinoma. The main indications of pancreatic ductal stenting are treatment of 'obstructive' pain in patients with dilated pancreatic duct beyond the stricture and intraluminal brachytherapy. The technique of endoscopic pancreatic drainage does not differ from that applied on the biliary aspect. Large bore plastic stents are preferred when possible. Only $15 \%$ of patients with advanced pancreatic cancer (55 of 355 in our experience) may benefit from this technique. Pancreatic stenting may be obtained in a high percentage of these selected patients $(81.8 \%)$ with low morbidity $(8.9 \%)$ and no mortality. According to our experiences and those of others reported in the literature, about $60 \%$ of patients treated for 'obstructive' pain experience disappearance of this symptom, and another $20 \%$ to $25 \%$ are able to reduce significantly the amount of analgesic drugs required. Intraluminal brachytherapy in the main pancreatic duct is a feasible and safe method to deliver high radiation doses to the tumour, sparing adjacent organs. It may be performed alone or as an adjuvant to external radiotherapy.

Multicentre studies are needed to determine whether intraluminal brachytherapy has any impact on survival.

18. Leahy LA, Carter CD. Review: pain and chronic pancreatitis. Eur J Gastroenterol Hepatol 1991;3:425-33.

19. Harrison MA, Hamilton SW. Palliation of pancreatic cancer pain by endoscopic stent placement. Gastrointest Endosc 1989;35:443-5.

20. Costamagna G, Gabbrielli M, Mutignani M, Perri V, Crucitti F. Treatment of obstructive pain by endoscopic drainage in patients with pancreatic head carcinoma. Gastrointest Endosc 1993;39:774-7.

21. Ashby K, Simon KC. The role of pancreatic stenting in obstructive ductal disorders other than pancreas divisum. Gastrointest Endosc 1995;42:306-11.

22. Lichtenstein DR, Slivka A, Banks PA, Carr-Locke DL. Pancreatic stent placement for palliation of "obstructive" pain in pancreatic malignancy. Gastrointest Endosc 1995;41:425. (Abst)

23. Tham TCK, Lichtenstein J, Vandervoort Wong RCK, Slivka A, Banks PA, Carr Locke DL. Pancreatic stents for palliation of "obstructive" pain in pancreatic malignancy. Gastrointest Endosc 1997;45:AB166. (Abst 565)

24. Alcocer E, Raijman L, Lahoti S, Hogan WJ, Geenen JE. Palliative endoscopic therapy in patients with pancreatic cancer and obstruction of the pancreatic duct using pancreatic stenting. Digestive Disease Week, Banff, May 17-20, 1998:A562. (Abst)

25. Asbuck SG. Overview of chemotherapy for pancreatic cancer. Int J Pancreatol 1990;7:209-22.

26. Borgelt BB, Dobelbower RR, Stubler KA. Betatron therapy for unresectable cancer. A preliminary report. Am J Surg 1978;135:76-80.

27. Haslam JB, Cavanaugh PJ, Stroup SL. Radiation therapy in the treatment of unresectable adenocarcinoma of the pancreas. Cancer 1973;32:1341-5.

28. Matsuda T, Tanaka Y. Intraoperative radiation therapy in combination with computer controlled conformation radiotherapy for pancreatic cancer. In: Dobelbower RR, Abe M, eds. Intraoperative radiation therapy. Boca Raton: CRC Press Inc, 1989;195-216.

29. Dobelbower RR, Borgelt BB, Strubel KA, Kitcher GS, Suntharalingam N. Precision radiotherapy for cancer of the pancreas: technique and results. Int J Radiat Oncol Biol Phys 1980;6:1127-33.

30. Dobelbower RR, Howard JM, Bagne FR, Eltaki A, Merrick HW. Treatment of cancer of the pancreas by precision high dose (PHD) external photon beam and intraoperative electron beam therapy (IOEBT). Int Radiat Oncol Biol Phys 1989;16:205-9.

31. Abe M, Takahashi M, Yabumoto E, et al. Techniques, indications and results of intraoperative radiotherapy of advanced cancers. Radiology 1975;116:693-702.

32. Kinsella TJ, Sindelar WF. Intraoperative radiotherapy for pancreatic 
carcinoma. Experimental and clinical studies. Cancer 1996;78:598-604.

33. Dobelbower RR Jr, Merrick HW, Ahuja RK, Skeel RT. 125 -I interstitial implant, precision high dose external beam therapy, and 5 FU for unresectable adenocarcinoma of pancreas and extrahepatic biliary tree. Cancer 1986;58:2185-95.

34. Mohiuddin M, Rosato F, Barbot D, Schuricht A, Biermann W, Cantor R. Long-term results of combined modality treatment with I-125 implantation for carcinoma of the pancreas. Int J Radiother Oncol Biol Phys 1992;23:305-11.

35. Montemaggi P, Dobelbower RR, Crucitti F, et al. Interstitial brachytherapy for pancreatic cancer; report of seven cases treated with 125-I and a review of the literature. Int J Radiat Oncol Biol Phys 1991;2:451-7.

36. Zimmon DS, Barsa J, Chang J, Clemett AR. The management of hepatic duct cancer with percutaneous transhepatic biliary stents and intraluminal radiation. Gastroenterology 1979;77:A59. (Abst)

37. Huibregtse K, Katon RM, Coene PP, Tytgat GNJ. Endoscopic palliative treatment in pancreatic cancer. Gastrointest Endosc 1986;32:334-8.

38. Deviere J, Baize M, De Toeuf J, Cremer M. Long-term follow-up of patients with hilar malignant stricture treated by endoscopic internal biliary drainage. Gastrointest Endosc 1988;34:95-101.

39. Cremer M, Deviere J, Delhaye M. Stenting in severe chronic pancreatitis: results of medium-term follow-up in seventy-six patients. Endoscopy 1991;23:171-6.

40. Ponchon T, Bory RM, Hedelius F. Endoscopic stenting for pain relief in chronic pancreatitis: results of a standardized protocol. Gastrointest Endosc 1995;42:452-6.

41. Duvall GA, Haber GB, Kortan P. Is the initial success of endoscopic therapy (ET) of chronic pancreatitis (CP) sustained in long-term follow up? Gastrointest Endosc 1996;43:404. (Abst 456)

42. Binmoeller KF, Jue P, Seifert H. Endoscopic pancreatic stent drainage in chronic pancreatitis and a dominant stricture: long-term results. Endoscopy 1995;27:638-44.

43. Smiths ME, Badiga SM, Rauws EAJ, Tytgat GNJ, Huibregtse K. Long-term results of pancreatic stents in chronic pancreatitis. Gastrointest Endosc 1995;42:461-7. 


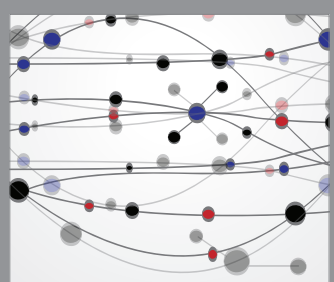

The Scientific World Journal
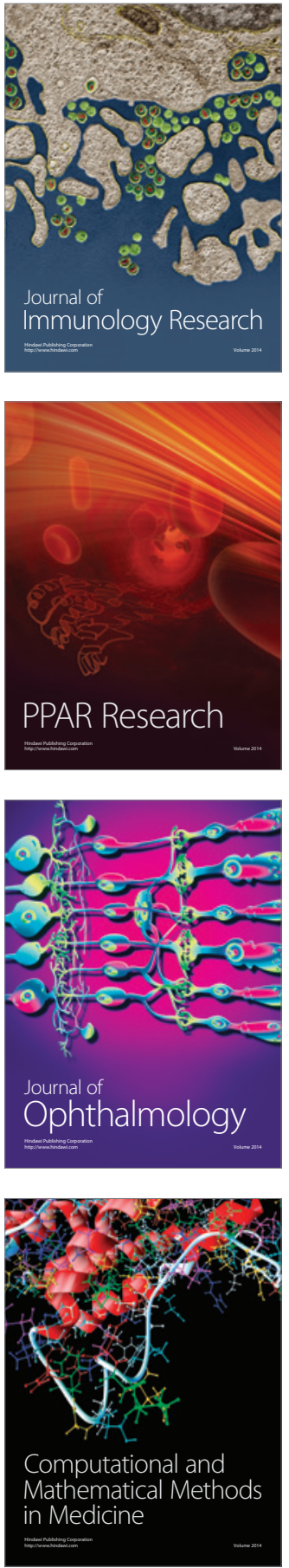

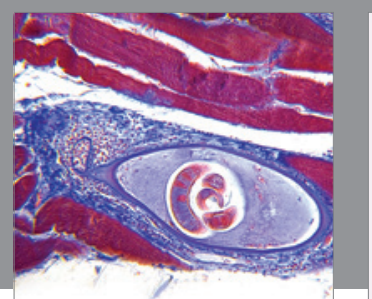

Gastroenterology Research and Practice

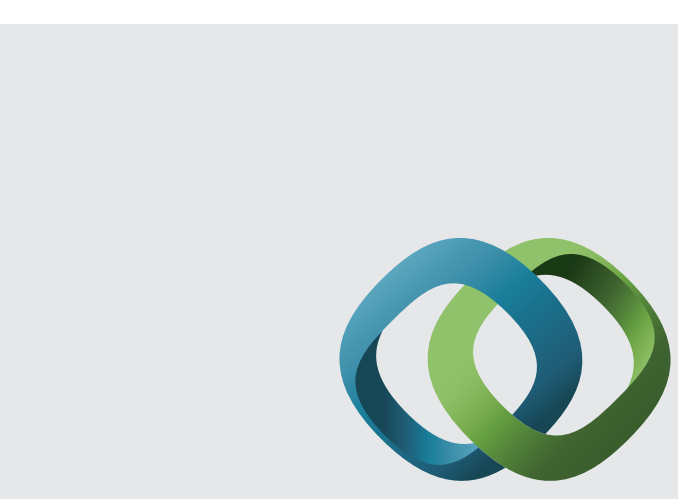

\section{Hindawi}

Submit your manuscripts at

http://www.hindawi.com
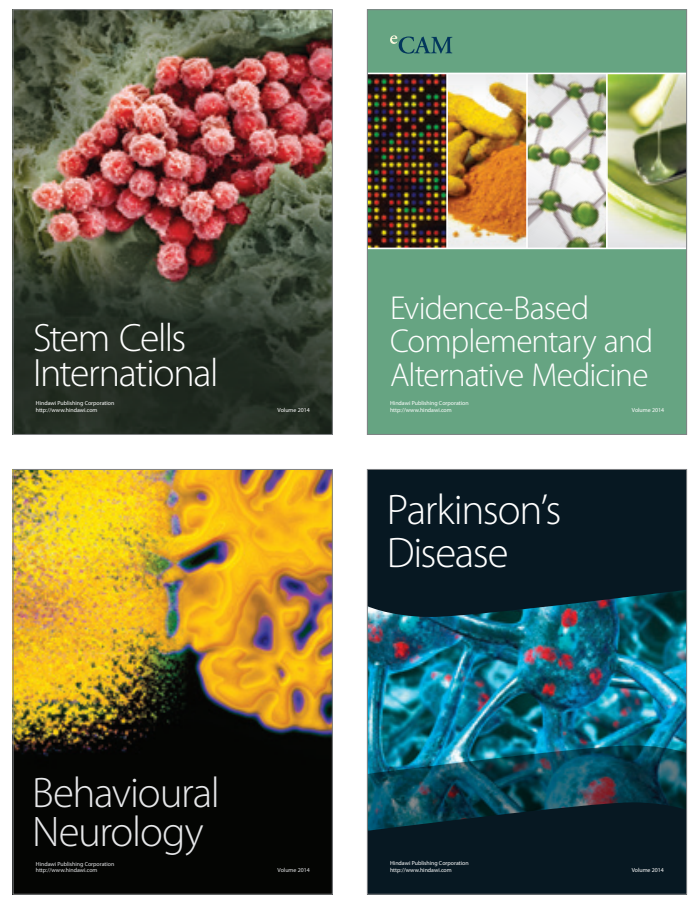
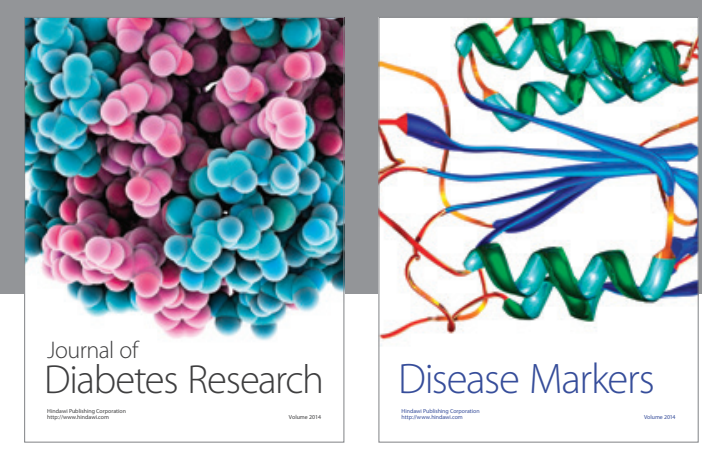

Disease Markers
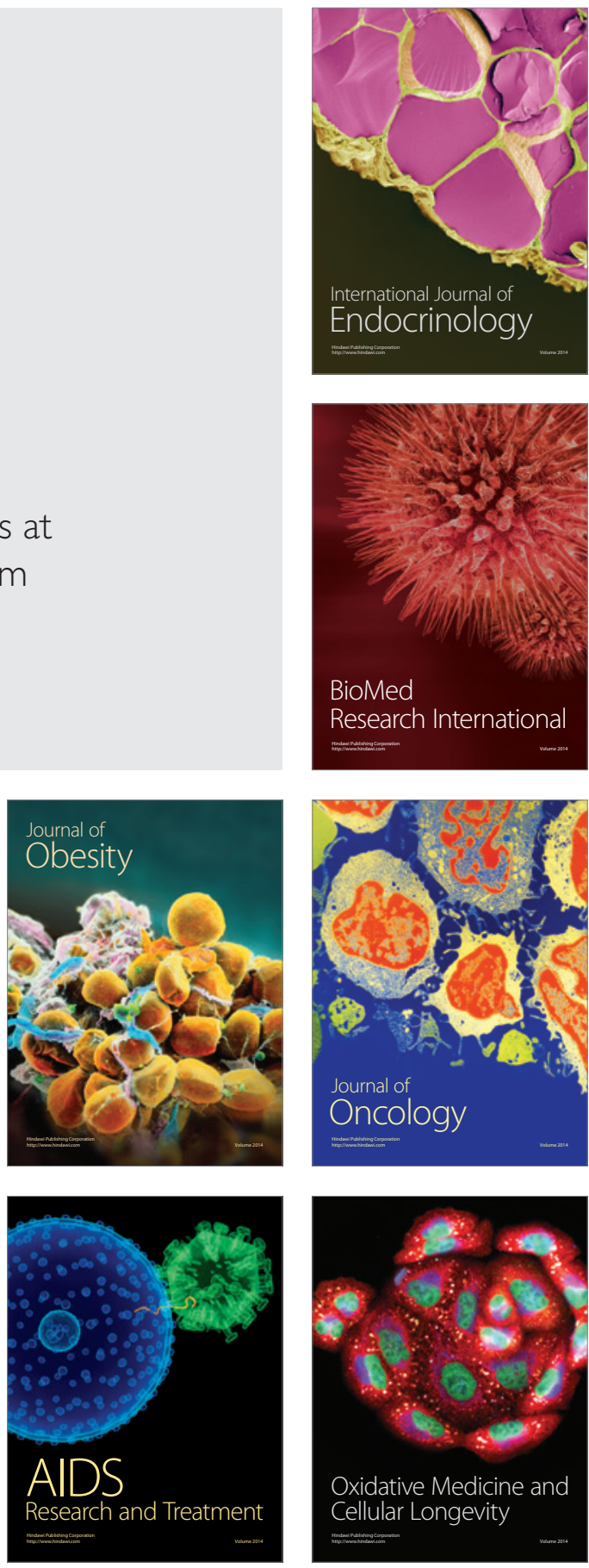